\title{
O envelhecimento e a prevenção do HIV/AIDS: um desafio para os profissionais de saúde
}

A epidemia do HIV/AIDS desde seu surgimento, na década de 80 , veio como uma doença estigmatizada e cheia de preconceitos. Inicialmente a AIDS foi chamada de doença dos $5 \mathrm{H}$, ou seja, que só afetava Homossexuais, Hemofílicos, Haitianos, Heroinômanos (usuários de heroína injetável), Hookers (profissionais do sexo em inglês), considerados na época "grupo de risco" para HIV/AIDS. Com o passar do tempo estudos avançaram em relação a temática e atualmente tem-se um panorama epidemiológico distinto. Atualmente a AIDS não é prevalente apenas nos "grupos de risco", termo este que não é mais utilizado, considera-se que existem vulnerabilidades de ordem individual, social e programática e que independente de raça, sexo, idade, opção sexual e condição socioeconômica, todos os indivíduos estão sujeitos à exposição ao HIV/AIDS.

De acordo com o boletim epidemiológico lançado pelo Ministério da Saúde no Dia Mundial de Luta Contra a AIDS, a maior concentração dos casos de AIDS no Brasil está entre os indivíduos com idade entre 25 a 39 anos, em ambos os sexos. Identificou-se também um aumento do número de casos de AIDS em pessoas com idade superior a 50 anos.

Neste contexto, compreende-se que a relação entre o envelhecimento e AIDS no Brasil está intimamente ligada à questão cultural e de exclusão, sobretudo o preconceito relacionado ao sexo nessa idade. Diversos estudos revelam que o desejo sexual permanece nas pessoas mais idosas e que a concepção que existe de que sexo é prerrogativa da juventude, contribui para manter fora das prioridades de prevenção das DSTs e AIDS este grupo populacional.

No Brasil caminhamos rapidamente para o envelhecimento populacional, e além de nos prepararmos para 0 aumento das doenças crônicas não transmissíveis, temos que estar atentos as doenças transmissíveis e desta forma qualificarmos as ações de prevenção e de promoção à saúde, principalmente no que se refere às Doenças Sexualmente Transmissíveis (DST) e HIV/AIDS.

Pensar em ações de prevenção relacionadas a DST/AIDS para a população idosa, constitui-se em um desafio para os profissionais de saúde, pois há que se romper essa barreira e pensar no idoso como uma pessoa que mantem sua sexualidade mesmo com todo processo de envelhecimento.

Nesta edição, a Revista Ciência \& Saúde conta com um estudo qualitativo que aborda a visão e prática de enfermeiro da estratégia saúde da família acerca da prevenção da AIDS em idosos, nos possibilitando uma interessante reflexão sobre as práticas de cuidado à população idosa.

Boa leitura!

Prof . MS ${ }^{a}$. Andrea Gonçalves Bandeira Professora do Curso de Enfermagem da FAENFI/PUCRS 